\title{
GIS based Irrigation Canal Alignment in Wayanad District, Kerala
}

\author{
Aravinda Bharathi .A ${ }^{1}$, Revathy .S .S ${ }^{2}$ \\ ${ }^{1}$ P.G. Student, Department of Civil Engineering, Adhiyamaan College of Engineering, Hosur, India \\ ${ }^{2}$ Assistant Professor,, Department of Civil Engineering, Adhiyamaan College of Engineering, Hosur, India
}

\begin{abstract}
Occurrence of prolonged droughts and floods in various parts of the country is primarily due to the improper management of water resources, which also hinders the growth of the nation. The only way to solve the issue is by constructing canal to the drought areas from the dam or rivers located nearby. The massive task of constructing canals requires multidisciplinary investigation on hydrological and agricultural factors that can be done using GIS and REMOTE SENSING. This project describes the design of a suitable path for construction canal from Karapuzha Dam in view of geomorphology, soil, land use and land cover pattern. Canals are also used for interlinking rivers. The digital information on topography, soils type, drainage pattern are obtained from SOI data and the land use/land cover pattern from LISS III image. 1 meter contours was prepared using ASTER DEM image. Digital Elevation Model (DEM) was extracted by interpolation from contour lines and used for horizontal and vertical alignment of the canal. The primary objective of the project is to identify the application capabilities of GIS in canal alignment. It also involves the estimation of agricultural and socio-economic benefits for the settlements in the reservoir basin.
\end{abstract}

Keywords: Canal Alignment, GIS, Irrigation Canal, Contour Canal

\section{Introduction}

A canal can be created where no stream presently exists. Either the body of the canal is dug or the sides of the canal are created by making dykes or levees by piling dirt, stone, concrete or other building materials. The water for the canal must be provided from an external source, like streams, lakes or reservoirs. India is blessed with abundant water resources, which are unevenly distributed in space and time. When one part of the country is reeling under severe water scarcity, floods damage another part. An irrigation canal is a waterway, often man-made or enhanced, built for the purpose of carrying water from a source such as a lake, river, or stream, to soil used for farming or landscaping. One of the difficulties with irrigation canals is providing a reliable flow of water. When the canal is directly connected to a water source like a lake or a river, the water supply is fairly reliable, but care must be exercised to avoid using so much water that other areas suffer. When an irrigation canal traverses a great distance or must navigate changes in elevation, other strategies must be employed. A contour canal is an artificially-dug navigable canal which closely follows the contour line of the land it traverses in order to avoid costly engineering works such as boring a tunnel through higher ground, building an embankment over lower ground, or constructing a canal lock (or series of locks) to change the level of the canal. Because of this, these canals are characterised by their meandering course.

\section{Study Area}

Wayanad is a district in the north-east of Kerala state. It is present in the southern tip of the Deccan Plateau. A Part of the district lies in Western Ghats. In the centre of the district, hills are lower in height while the northern area has high hills. The eastern area is flat and open. Thus the study area extends from $76^{\circ} 5^{\prime}$, to $76^{\circ} 10^{\prime}$ East Longitude and $11^{\circ} 35^{\prime}$ to $11^{\circ} 40^{\prime}$ North Latitude. Quite a large area of the district is covered by forest but the continued and indiscriminate exploitation of the natural resources point towards an imminent environmental crisis. It has a large amount of dry and moist deciduous forest. Wayanad is home to endangered species.

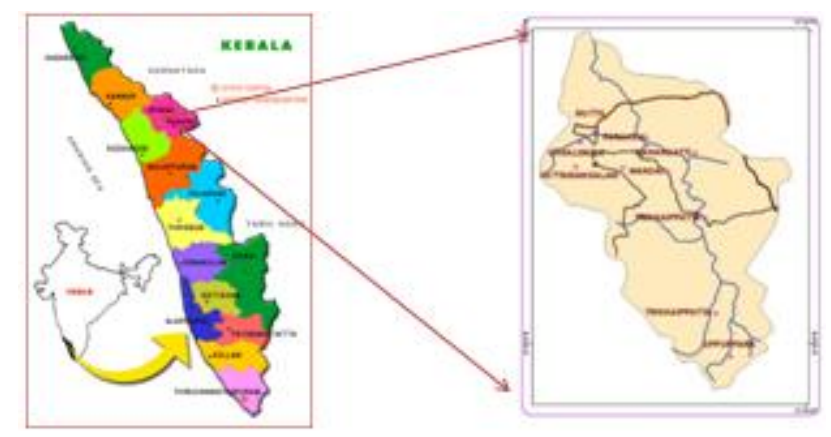

\section{Materials and Methodology}

The database is generated with the help of LISS III Satellite data, SOI Toposheets, and contour data generated using ASTER-DEM. The contents generated for the case of Landuse, Geomorphology, Landform, Drainage and Watershed. Lithology, Structure and soil data is generated in 1:50,000 and the Road and Settlements data is developed from high resolution CARTOSAT and Quick Bird data. 


\section{International Journal of Science and Research (IJSR) ISSN (Online): 2319-7064}

Index Copernicus Value (2013): 6.14 | Impact Factor (2014): 5.611

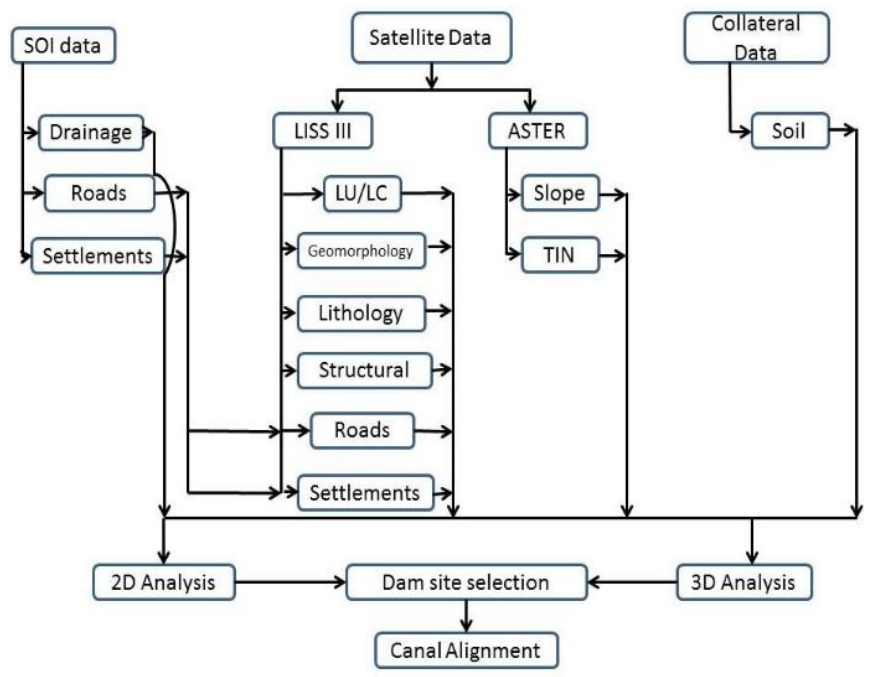

\section{Canal Path Alignment}

\section{Main Canal Alignment}

Two elevation points on the reservoir's Left and Right side for tapping the stored water was identified and is fixed by estimating 'crop water requirements' of the crops cultivated in left side and right side of the ayacut area of the reservoir .The point identified is based on the crop water requirement is 737 meters. The particular contour line carrying the elevation values of reservoir left side tapping point and was broken at the intersection point of reservoir storage. The contour line thus divides into two segments, one on the catchment side and other on adjacent area side. Further one segment of the divided contour line which passing through the ayacut area was selected and was segmented at 4000 meters from the tapping point of the reservoir and was connected with the next lowest (736 meter in this case) value contour at the end point or after 4000 meters. Again the lowest value contour (736 meter) was broken into two segments at the intersection point of the higher value contour and the segment of the divided contour which is not parallel to the previous 4000 meters segment was again segmented at 4000 meters and connect to the end point of first 4000 meter segment. This step of breaking the contours at 4000 meters and connecting to the upper segment is repeated to the end of ayacut.

\section{Aqueduct and Cut on Main Canal}

The semi parabolic profile of the main canal can be reshaped by introducing Aqueduct or cut on the main canal. This will shorten the length of the main canal and reduce cost.

\section{Branch and Distributaries from Main Canal:}

Branch canals and Distributaries from main Canal network will be introduced in watershed wise if the canal is not enough to irrigate the adjacent lands along the channel.

\section{Results and Discussion}

\section{Right Bank Canal}

\begin{tabular}{|c|c|}
\hline Main canal length & 9496.38 meters \\
\hline Number of Aqueducts & 2 \\
\hline Number of Cuts & 1 \\
\hline Number of Break Points & 2 \\
\hline
\end{tabular}

\section{Left Bank Canal}

\begin{tabular}{|c|c|}
\hline Main canal length & 10830.06 meters \\
\hline Number of Aqueducts & 2 \\
\hline Number of Cuts & 2 \\
\hline Number of Break Points & 2 \\
\hline
\end{tabular}

Thus the canal for both Right and Left banks of the dam are routed along the contour lines with the Right bank canal has the total length of 9496.38 meters whereas Left bank canal has its length of 10830.06 meters. Since the canals in the Left and Right side bank have two Aqueducts each. The Left Bank canal has two cuts and Right bank canal have one cut.
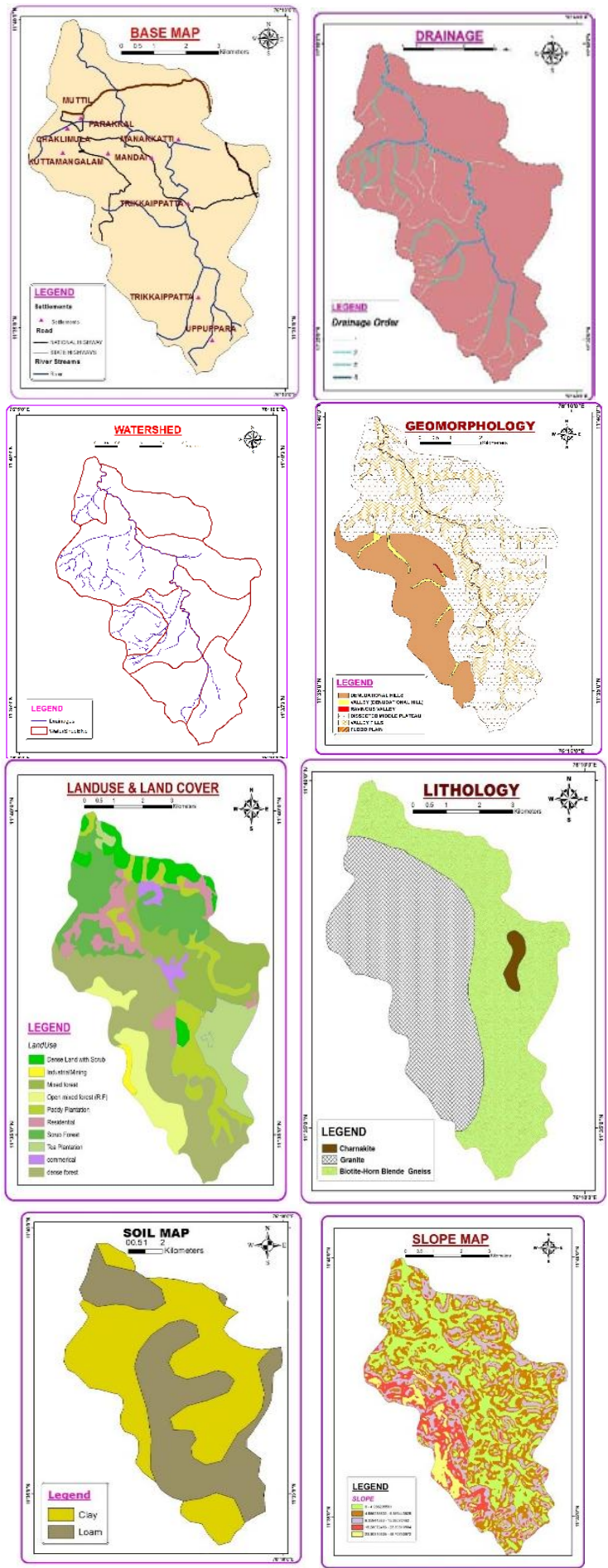


\section{International Journal of Science and Research (IJSR) \\ ISSN (Online): 2319-7064}

Index Copernicus Value (2013): 6.14 | Impact Factor (2014): 5.611

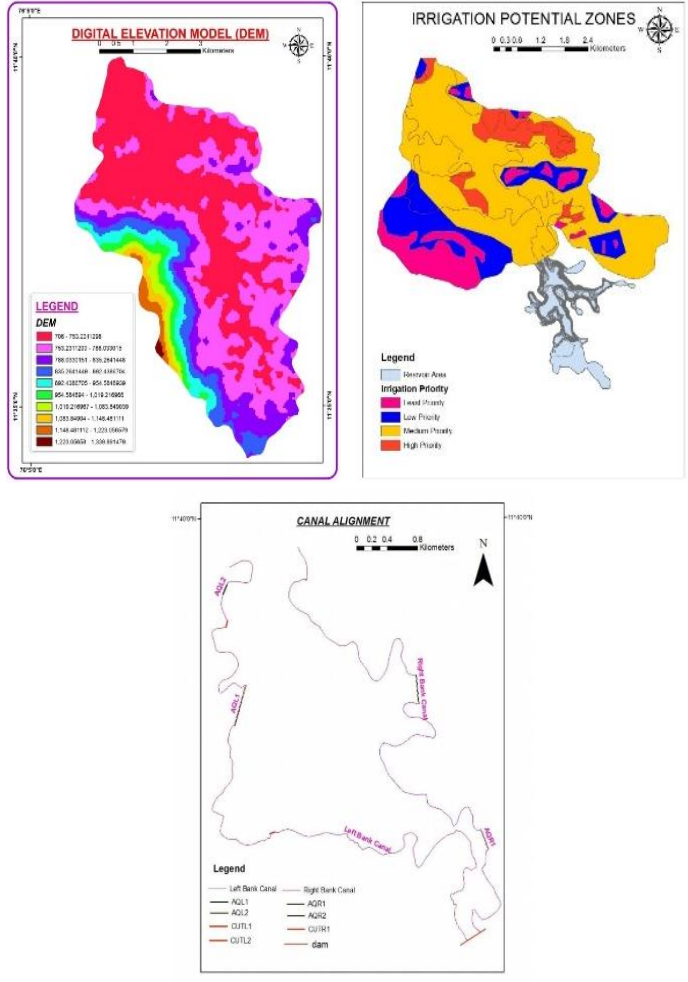

\section{Conclusion}

The study analysed the canal building procedures in Wayanad district. It serves to control drought in future. It defines the canal path and the Optimum usage of water has to be facilitated by distribution channel up to the agricultural field from the canals. It is worthwhile to plan for domestic water supply to towns and villages and enroute it to use for both irrigation and other purposes. Water supply network can be planned in GIS environment to carry out route tracing and resource allocation in an efficient manner. "Water is the gift to humans" it deserves a better management for the progress of the nation and usage of effective technologies. GIS might provide the answers to all the problems.

\section{References}

[1] Ajoy Das, Milan Mondal, Bhaskar Das, Asim RatanGhosh" Analysis of drainage morphometry and watershed prioritization in Bandu Watershed, Purulia, West Bengal through Remote Sensing and GIS technology - A case study" International Journal Of Geomatics And Geosciences Volume 2, No 4, 2012.

[2] AkramjaJaved, MohdyousufKhanday\&Subahrais" Watershed prioritization using morphometric and land use/land cover parameters: a Remote sensing and GIS based approach" journal geological society of India $\mathrm{v}$ ol.78, July 2011.

[3] G. AshenafiTolessa \& P. Jagadeeswara Rao" Watershed development prioritization of Tandava river basin, Andhra Pradesh, India - gis approach" international journal of engineering science invention, volume 2 ,issue 2 ,February 2013.

[4] Majunu S and Sumanth Kumar G, College of Engineering, Anna University, Chennai. - Canal alignment using geographical information system.
[5] N Vinayachandran, Sc. 'B' And Dr. V.S. Joji, Sc. 'B' Ground Water Information Booklet Of Wayanad District, Kerala State 